\title{
PCM-Based Energy Storage System with High Power Output Using Open Porous Aluminum Foams
}

\author{
Joachim Baumeister ${ }^{1}$, Jörg Weise ${ }^{1, *}$, Sebastian Myslicki ${ }^{1}$, Esther Kieseritzky ${ }^{2}$ and \\ Götz Lindenberg ${ }^{2}$ \\ 1 Fraunhofer Institute for Manufacturing Technology and Advanced Materials (IFAM), D-28359 Bremen, \\ Germany; joachim.baumeister@ifam.fraunhofer.de (J.B.); sebastian.myslicky@ifam.fraunhofer.de (S.M.) \\ 2 Rubitherm Technologies GmbH, D-12307 Berlin, Germany; esther.kieseritzky@rubitherm.com (E.K.); \\ goetz.lindenberg@rubitherm.com (G.L.) \\ * Correspondence: joerg.weise@ifam.fraunhofer.de
}

Received: 4 September 2020; Accepted: 23 November 2020; Published: 25 November 2020

\begin{abstract}
Thermal comfort (heating, ventilation and air conditioning, HVAC) and the energy consumption involved with it can put a strain on the driving range of fully electric vehicles (FEV), especially in certain times of the year as midsummer or winter. In order to reduce the energy consumption of HVAC, improved thermal management and adapted means of energy storage are needed. One part of the solution can be the use of phase change materials (PCM) for storing waste heat. For the specific application, however, a high loading/unloading power rate is required, which is challenging as the PCMs exhibit low heat conductivities. In the presented work, a storage demonstrator system was investigated which is part of an HVAC system of a specific fully electric vehicle. The profile of requirements of the system (power, stored capacity and allowed volume) make a new design of the storage necessary. Two demonstrator units, in which the PCM was combined with aluminum foam, were manufactured and their power output in dependency on the fluid flow of the coolant system was compared. An adapted squeeze casting process with polymer placeholders was used for the production of the aluminium foam. This process results in foams with a specific pore structure and allows the in-situ integration of the heat transfer fluid (HTF) pipes. Both newly developed PCM storage systems satisfy the HVAC system requirements.
\end{abstract}

Keywords: aluminum foam; open porosity; thermal conductivity; phase change material; latent heat storage

\section{Introduction}

In electric vehicles the thermal management system for the interior of the vehicle can consume a significant amount of energy from the battery, especially for heating in cold winter conditions or for cooling in hot summer conditions (e.g., at an ambient temperature of $-10{ }^{\circ} \mathrm{C}$ and $+40{ }^{\circ} \mathrm{C}$, respectively). Therefore, the heating, ventilation, and air conditioning (HVAC) system can significantly reduce the maximum driving range of the vehicle. In order to mitigate this problem, several measures have been proposed as e.g., enhanced thermal insulation of the car or use of radiation heating in addition to the existing convection systems. An additional promising approach is the storing of thermal energy in suitable systems using phase change materials (PCM). Several sources of thermal energy are available in electric vehicles; e.g., heat developing during the charging of the battery or residual heat in the car after the end of a journey. The stored thermal energy, in turn, can be used for heating the passenger compartment when the car is started again.

Thermal storage systems with PCM are a well-established means for the cooling of buildings [1,2]. Another application example is the thermal stabilization of temperature sensitive goods during 
transport [3]. However, for applications in electric vehicles a higher loading/unloading power rate is required. Unfortunately, most of the suitable PCM materials have low heat conductivities, which hampers a high loading/unloading rate. Furthermore, in vehicles, strict space and weight limitations must be met.

In the EU-funded project "QUIET" a PCM based thermal storage system had to be designed and developed which can deliver around $500 \mathrm{~W}$ of heat power for a period of $5 \mathrm{~min}(42 \mathrm{Wh}$ minimum capacity). The maximum allowed storage size including insulation is $490 \times 275 \times 80 \mathrm{~mm}$. The usable temperature range of the storage medium needs to be between $15^{\circ} \mathrm{C}$ and $20^{\circ} \mathrm{C}$.

In order to meet these requirements the overall thermal conductivity of the PCM based thermal storage system had to be increased. Common approaches are to disperse particles with high thermal conductivity in the PCM, encapsulating the PCM or to combine the PCM with macroscopic structures featuring high thermal conductivities, like metals or graphite [4-13]. In the case of metals a variety of structures, e.g., lamella heat exchangers, foams, fibre structures or honeycombs, and alloys (mostly Al, $\mathrm{Cu}$ or stainless steel) have been tested. However, which structure and which alloy will be optimal cannot be answered in a general way as this depends on parameters and requirements of the storage system e.g., installation space, power output, working temperatures, or the reactivity of the PCM.

In preliminary tests of the presented work three different combinations of a paraffin-based PCM (Rubitherm RT18HC) with conduction-increasing structures were compared: PCM-infiltrated graphite, a PCM-filled lamellae heat exchanger, and a PCM-filled aluminium foam. In comparison the PCM filled aluminium foam met the command variable power output most closely [14]. The 3-dimensional metallic structure of the foam acts as a highly conductive skeleton or scaffold and can significantly increase the performance of the PCM storage system. The high potential of aluminium foams for the application in PCM storage systems has already been shown in different investigations, e.g., [15]. In conventional latent heat storage systems, equipped only with PCM, the thermal conductivity of the PCM is the dominating part of the overall chain of thermal resistance. Integrating metal foam into the PCM will decrease this resistance dramatically so that other resistances become more prominent. It was shown that smaller pore sizes of the metal are advantageous $[13,16]$. This is due to the fact that - with the high integral thermal conductivity of the PCM-foam-composite-the transport length of the heat from the PCM in the pore to the metal foam plays a more important role. Furthermore, the small temperature gradients in PCM-foam-volumes indicate that the transfer of the heat into the heat transfer fluid (HTF) system is the limiting factor in this case, as shown, e.g., by [9,15].

In many of the cited investigations related to combinations of PCM-foam $\mathrm{Al}$ and $\mathrm{Cu}$ foams were used, which have strut-dominated structures (less fraction of lamellas). This is due to the production of such foams using e.g., investment casting with special polymer foam models. Furthermore, often the bonding of the foam to the HTF system (e.g., tubes) has not been considered. Bonding of foam structures with their struts and lamellas can be quite difficult, especially if complex HTF-tube geometries as non-circular tube sections or bended tubes are considered.

In the present work a different approach has been followed. An adapted squeeze casting process is used to produce foam structures with combined strut-lamella-geometries. This process as a variant of the well-established high pressure die casting is not only highly efficient, it also allows the in-situ integration of tubes into the originating metal foam structure. As was shown by Rübner and Körner, a good metal-metal bonding can be obtained in this way ensuring also a good thermal contact $[17,18]$. Two different demonstrator storage systems, based on paraffin PCM and the described aluminium foam, were produced and their thermal behaviour during charging and discharging was investigated and compared. To give insights about the relation of the PCM latent heat release and the increase of the heat transfer fluid (HTF) temperature at the outlet during discharging process, a numerical model is presented. In this model the geometric complexity is strongly simplified but nevertheless meets the experimental results. 


\section{Materials and Methods}

The above-mentioned open porous aluminium foams were produced at IFAM by means of infiltration of aluminium melt into polymer structures using a place-holder/high-pressure-die-casting process [19]. At first, a porous near-net-shape compact is formed from polymer granules, Figure 1 (left). This porous polymer preform is then infiltrated with molten metal using a high-pressure-die-casting machine. The high infiltration speed and the high solidification rate of the casting process inhibit the melting of the polymer granules. After removing the gating system and casting skins by machining, the polymer granules are thermally removed also. This means that the polymer compact in Figure 1 (left) acts as a place-holder, it represents the later pore structure and is the negative form of the final open-porous metal foam (right).

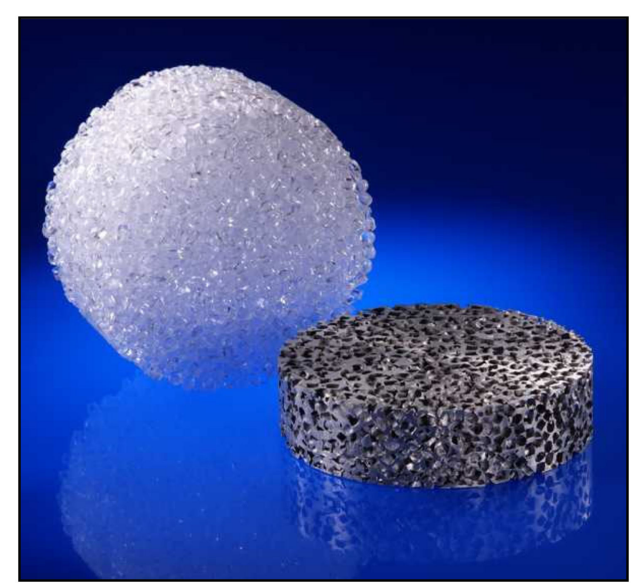

Figure 1. Polymer preform (left) and open porous aluminum foam (right).

Using this manufacturing process it is possible to adjust the pore size and the porosity by proper preparation of the polymer preform. In comparison to other methods for foam production like investment casting or casting into salt-placeholder structures, it is easy to remove the place holder resp. mould material completely and without residues. As already mentioned, fluid ducts like tubes can easily be integrated into the preform. After the casting step and removal of the polymer the tubes are tightly embedded in the metallic foam structure.

The first demonstrator storage system consists of 26 aluminium foam bodies with dimensions $105 \times 80 \times 14 \mathrm{~mm}$-each of them containing one aluminium pipe (inner diameter $6 \mathrm{~mm}$ ) for the coolant. The size of the polymer granules (polystyrene, Biesterfeld Plastic $\mathrm{GmbH}$ ) and thus the later pore size was selected to be $3 \mathrm{~mm}$; the targeted porosity was $65 \%$. The polystyrene preforms with embedded tubes were sintered in a rectangular mould at $150{ }^{\circ} \mathrm{C}$ and are shown in Figure 2 (left). The infiltration with aluminum melt (AlSi10MnMg, Rheinfelden) was done using a high pressure die casting machine (Bühler 660) operating at a pressure of 250 bars and under real-time-control. The casting speed was $0.25 \mathrm{~m} / \mathrm{sec}$; the melt temperature was $720^{\circ} \mathrm{C}$. After the infiltration step, the gating system and casting skins were removed by machining, afterwards the polystyrene granules were thermally removed. The resulting open porous aluminum foams with embedded tubes are shown in Figure 2 (right). 


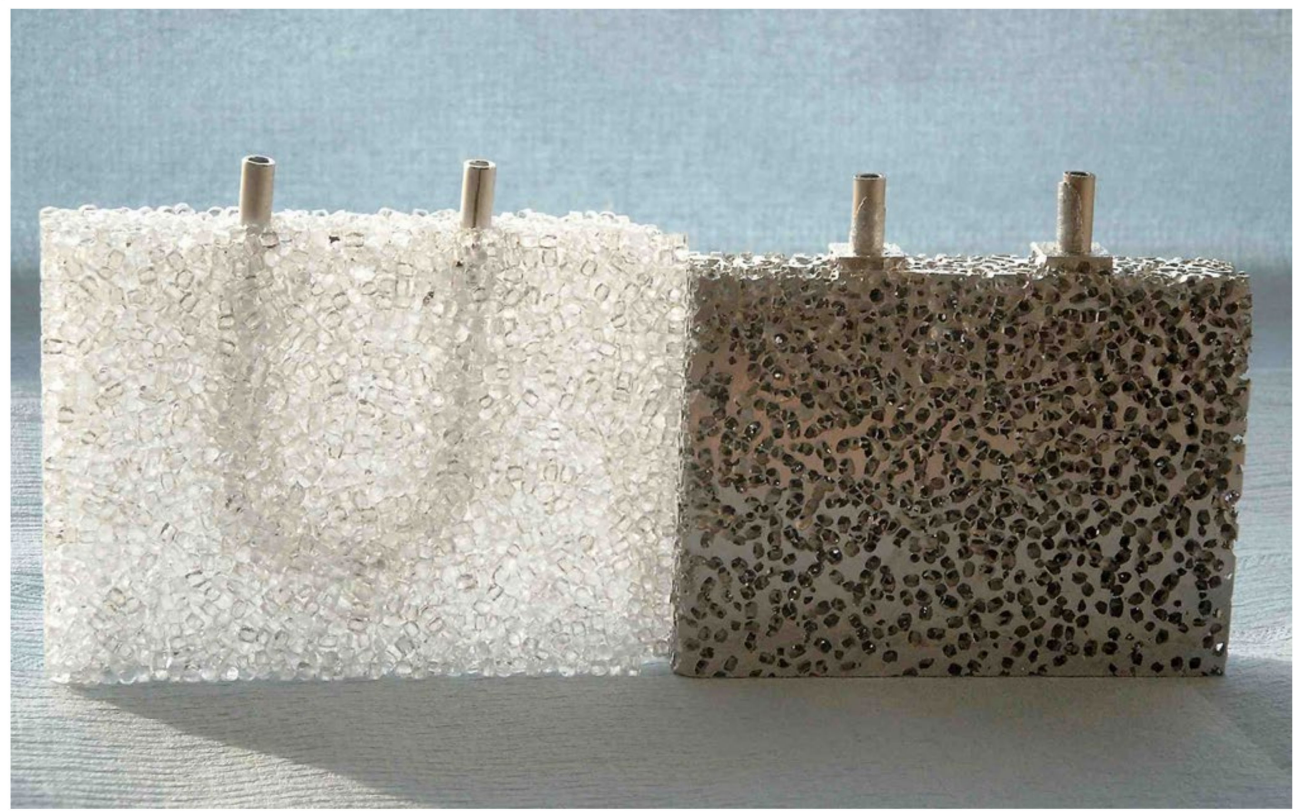

Figure 2. Polymer preforms (left) and open porous aluminum foams (right) with embedded tubes, for the $26 \mathrm{p}$-system.

In principle, the large number of smaller bodies allows a comparison of serial and parallel connections and a mix of these two. In the further discussion only the serial connection will be examined. The interconnection of the 26 foam parts (26p storage) requires 52 connections as each aluminium pipe is connected to a rubber hose which is then in turn connected to the next aluminium pipe. This leads to several design difficulties: 1 . All connections have to be watertight. 2 . The tightening should not influence the inner diameter of the pipes leading to pressure loss. 3 . The space needed for the number of connections takes up much room in the limited space available.

In the second demonstrator system only 4 foam parts (4p storage) with the dimensions $170 \times 90 \times$ $40 \mathrm{~mm}$ were used (Figure 3). Each of the foams contains 2 aluminium pipes (inner diameter $6 \mathrm{~mm}$ ) for the coolant. This results in a total of 16 necessary connections within the storage. The porosity of the obtained foams is $75 \%$ on average. The production followed the process used already for the $26 \mathrm{p}$-demonstrator. The aluminium tube length in the $26 \mathrm{p}$ storage is $410 \mathrm{~cm}$, in the $4 \mathrm{p}$ storage $240 \mathrm{~cm}$.

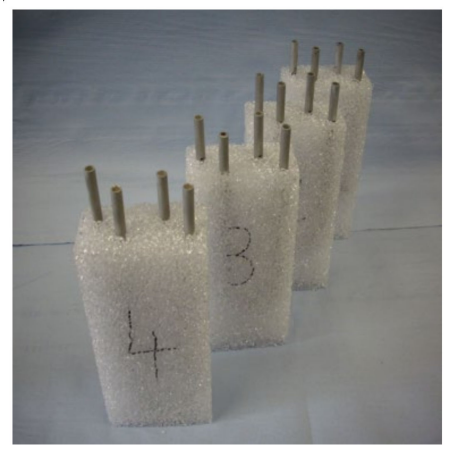

(a)

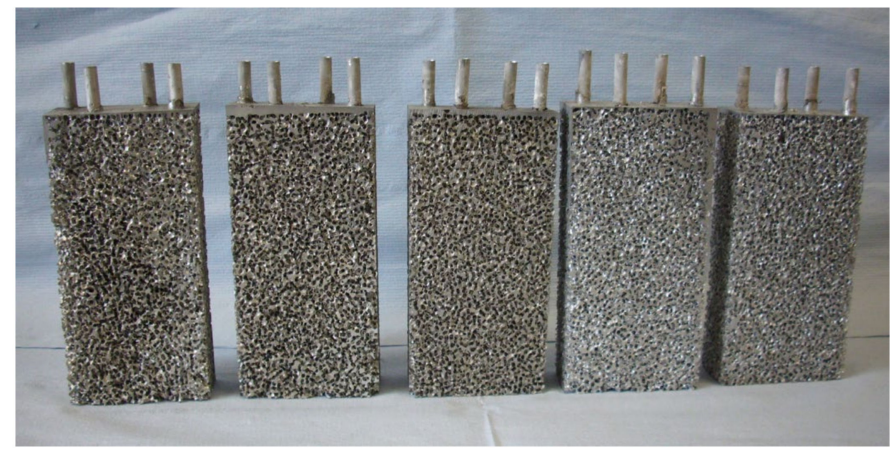

(b)

Figure 3. Polymer preforms (a) and open porous aluminum foams (b) with embedded tubes, for the 4 p-system.

For filling the aluminum foam samples the paraffin-based PCM RT18HC (Rubitherm Technologies $\mathrm{GmbH})$ with a latent heat of approx. $230 \mathrm{~kJ} / \mathrm{kg}(64 \mathrm{Wh} / \mathrm{kg})$ in the temperature range between 16 and $19^{\circ} \mathrm{C}$ and a narrow melting/solidification range around $18^{\circ} \mathrm{C}$ was selected. To keep the PCM inside the 
foams during subsequent freeze-thaw-cycles $10 \%$ polybutadiene-based thickening agent was added to increase the viscosity of the RT18HC. All samples of the Al foams were filled with PCM using multistep vacuum infiltration. The foams filled this way were wrapped in aluminium foil and could thus be installed leak-proof into a box, see Figure 4. The outer box is lined with melamine resin foam for thermal insulation. This, however, is more important for later practical tests with the demonstrator car (Model 2013 Honda Fit EV, Market North America, small series, Motor power 92 kW, Battery cap.20 $\mathrm{kWh}$ ) than for the presented lab performance tests as those were carried out without any holding times after charging or discharging of the systems.

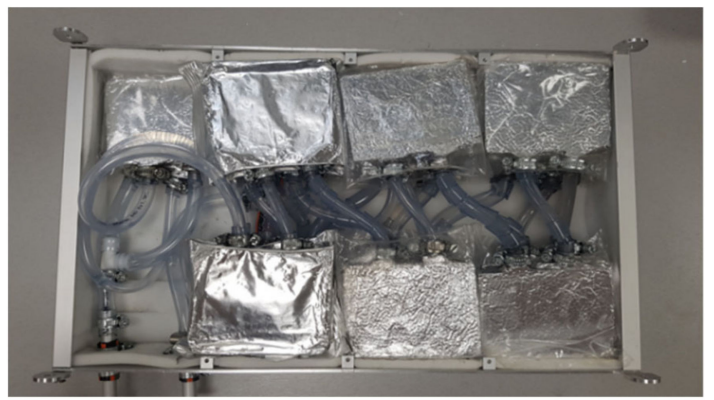

(a)

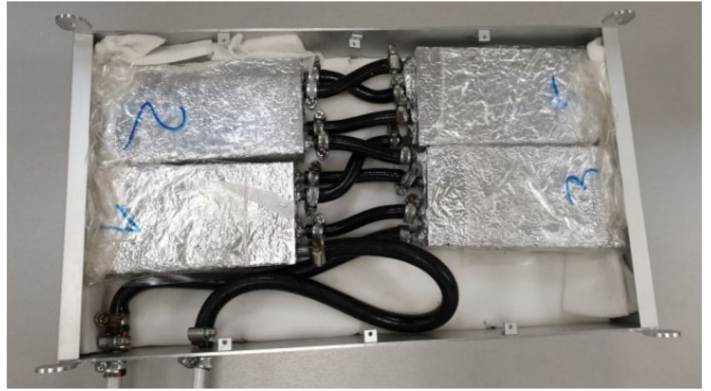

(b)

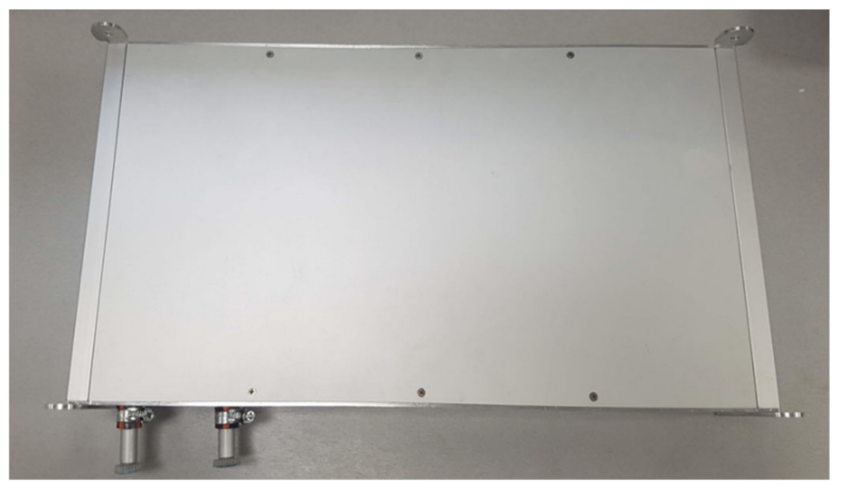

(c)

Figure 4. Thermal storage unit containing phase change material (PCM)-filled aluminum foams, (a) stacking and (b) connection situation, (c) finished unit.

The specific parameters of both demonstrator systems are summarized in Table 1 . The overall thermal capacities of the $26 \mathrm{p}$ and $4 \mathrm{p}$ systems in the temperature range of the experiment $\left(8{ }^{\circ} \mathrm{C}-28^{\circ} \mathrm{C}\right.$, see below) are 119 Wh resp. $102 \mathrm{Wh}$. This overcapacity in comparison to the minimum capacity (42 Wh) was used in order to achieve the required performance within the specified timeframe.

To determine power-heat curves of the PCM storage the systems were charged (melting of PCM) and discharged (solidification of PCM) using water reservoirs with temperatures above $\left(28^{\circ} \mathrm{C}\right)$ and below $\left(8^{\circ} \mathrm{C}\right)$ the melting point of the PCM. The charging and discharging tests were done alternatingly and repeated several times. Charging resp. discharging was done in one cycle until the temperatures at inlet and outlet did not change anymore. Then the temperature of the thermostat was changed. It reached a constant temperature after $30 \mathrm{~min}$, then the reverse process was started and documented. During charging and discharging the water temperatures at the entrance and exit of the storages were measured using K-type KT-100 thermocouples ( $0.2 \mathrm{~K}$ resolution) bonded with thermal adhesive to the surface of the aluminium tubes at the inlet and outlet of the storage system. Data processing was done with a Comark N2014 system with a temperature resolution of $0.2 \mathrm{~K}$. Together with the measured volume flow, the temperature differences were used to determine the power uptake or release during the measurement as well as the accumulated stored or released heat. 
Table 1. Parameters of the demonstrator systems 26p and 4p.

\begin{tabular}{ccc}
\hline Property & 26p-System & 4p-System \\
\hline Foam block number & 26 & 4 \\
\hline Appr. block dimensions & $105 \mathrm{~mm} \times 80 \mathrm{~mm} \times 14 \mathrm{~mm}$ & $170 \mathrm{~mm} \times 90 \mathrm{~mm} \times 40 \mathrm{~mm}$ \\
\hline Porosity & $65 \%$ & $75 \%$ \\
\hline Overall Al mass & $2340 \mathrm{~g}$ & $1700 \mathrm{~g}$ \\
\hline PCM RT18HC mass & $1404 \mathrm{~g}$ & $1215 \mathrm{~g}$ \\
\hline Thickener mass & $156 \mathrm{~g}$ & $135 \mathrm{~g}$ \\
\hline Al tube inner/outer diameter & $6 \mathrm{~mm} / 8 \mathrm{~mm}$ & $6 \mathrm{~mm} / 8 \mathrm{~mm}$ \\
\hline Al tube length & $410 \mathrm{~cm}$ & $240 \mathrm{~cm}$ \\
\hline $\begin{array}{c}\text { Overall capacity incl. latent and } \\
\text { sensitive heat }\left(8^{\circ} \mathrm{C}-28{ }^{\circ} \mathrm{C}\right)\end{array}$ & $119 \mathrm{Wh}(428 \mathrm{~kJ})$ & $102 \mathrm{Wh}(367 \mathrm{~kJ})$ \\
\hline
\end{tabular}

Additionally to the measurements with the $20 \mathrm{~K}$-temperature difference, another, more qualitative test was done, simulating a thermal load case with a continuous change of inlet-temperature to a final, relatively small temperature level of $4 \mathrm{~K}$ above resp. $4 \mathrm{~K}$ below the melting point of $18^{\circ} \mathrm{C}$ of the PCM (tests are labelled $+4 \mathrm{~K}$ and $-4 \mathrm{~K}$ ).

The measurements for each experimental parameter set have been repeated at least 5 times. In order to exclude systematic errors, balance of energy estimations were carried out.

For a better understanding of the correlations between the different parameters of the system and their impact on the overall system, behaviour simulation studies are helpful. However, such studies cannot easily be applied on the actual system design. e.g., changing the tube length in the actual foam-tube-design is very complicated and not unambiguous (several designs modifications can be used to obtain the same tube length variation). Therefore, it was tested if a strongly simplified geometrical model can be used to describe the actual observed thermal behaviour of the $4 p$-system. The basic idea is that certain foam-PCM-regions of each block can be allocated to each tube segment (like a watershed process). Because of the rather symmetric position of the tubes in the foam block it was decided to use the very simple model of one long tube embedded in a cylindrical foam-PCM volume.

All geometrical (foam volume, tube dimensions) and material parameters (masses, $\lambda, c_{a p}, \rho$, latent heat) of the model were adopted from the experiments. The $4 \mathrm{p}$-modules are in fact four blocks of PCM-foam-composite, which are penetrated by several aluminium pipes joined serially. The thermal energy in this system can be represented by the latent heat of the PCM and the sensible heat of the PCM, aluminium foam and aluminium pipe. As described above, it is assumed that all PCM-modules can be numerically represented by an axisymmetric cylinder. The outer radius of the cylinder was set to $r_{\text {pcm/foam }}=17.83 \mathrm{~mm}$ as it results in the same volume for PCM/foam regime as in the experimental setup. The pipe length of $L=2400 \mathrm{~mm}$ and the inner radius $r_{\text {inner pipe }}=3 \mathrm{~mm}$ and outer pipe radius $r_{\text {router pipe }}=4 \mathrm{~mm}$ were also identical to the experiments. The geometrical model is depicted in Figure 5 .

The PCM/foam domain is considered to be a homogenous composite. The derived material parameters for this PCM/foam-composite are presented in Table 2. The following correlations were used to calculate the properties of the PCM/foam domain from the parameters of the PCM and the aluminium foam

$$
\begin{gathered}
\rho_{e f f}=\varphi_{P C M} \times \rho_{P C M}+\left(1-\varphi_{P C M}\right) \times \rho_{A l} \\
c_{p, e f f}=\frac{\varphi_{P C M} \times \rho_{P C M} \times c_{p, P C M}+\left(1-\varphi_{P C M}\right) \times \rho_{A l} \times c_{p, a l}}{\rho_{e f f}} \\
L_{F o a m / P C M}=\frac{\varphi_{P C M} \cdot\left(\rho_{P C M} \cdot L_{P C M}\right)}{\rho_{e f f}}
\end{gathered}
$$




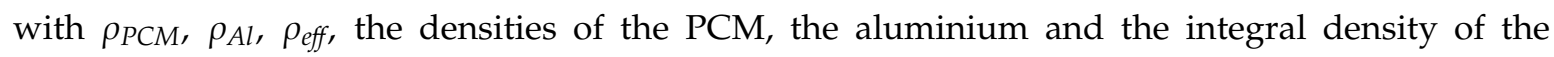
PCM-foam-volume, $\varphi_{P C M}$ the volume fraction of PCM, $c_{p, P C M}, c_{p, A l}, c_{p, e f f}$ the specific thermal capacities of respective phases and $L_{P C M}, L_{F o a m / P C M}$ the latent heat of the PCM and the PCM-foam-volume.

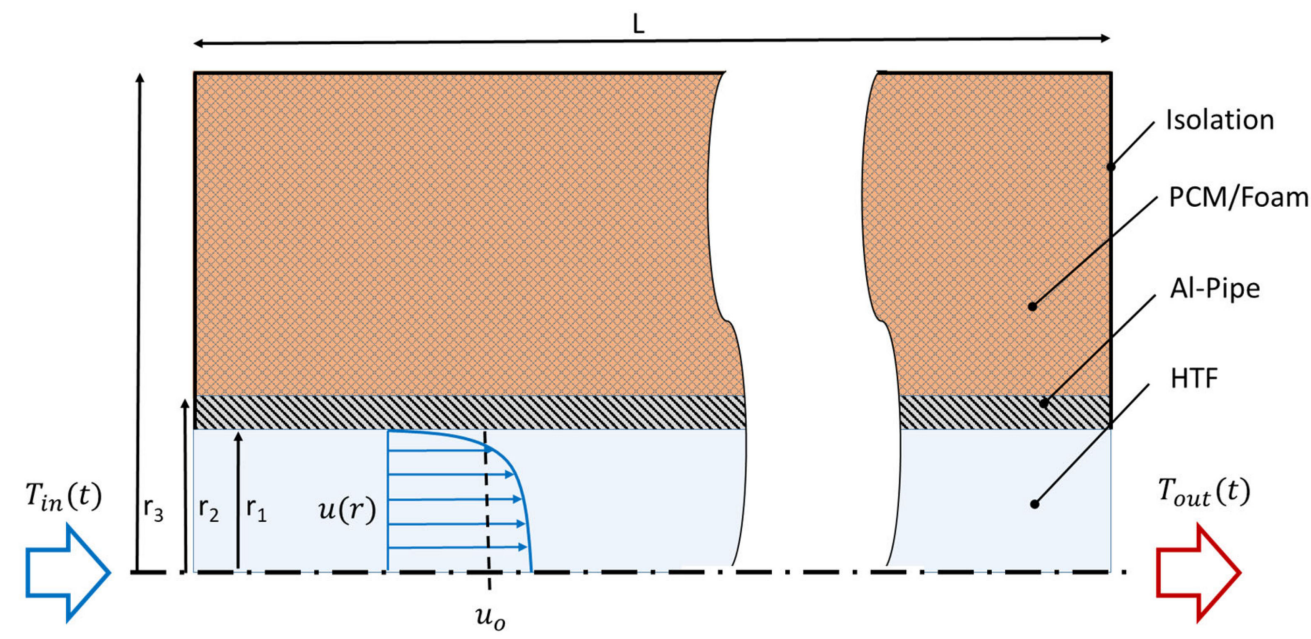

Figure 5. Geometrical simulation model.

Table 2. Material parameters.

\begin{tabular}{cccccc}
\hline Physical Quantity & Al (Tube) & Water (HTF) & $\begin{array}{c}\text { AlSi10MnMg } \\
\text { (Foam) }\end{array}$ & $\begin{array}{c}\text { RT18HC } \\
(\text { PCM) }\end{array}$ & $\begin{array}{c}\text { PCM/Foam } \\
(\boldsymbol{\phi}=\mathbf{7 5} \%)\end{array}$ \\
\hline Density, $\rho\left(\mathrm{kg} / \mathrm{m}^{3}\right)$ & 2719 & 998 & 2680 & 790 & 1260 \\
\hline Specific heat, $c_{p}(\mathrm{~J} / \mathrm{kgK})$ & 871 & 4182 & 880 & 2000 & 1410 \\
\hline $\begin{array}{c}\text { Thermal conductivity, } \lambda \\
(\mathrm{W} / \mathrm{mK})\end{array}$ & 202 & 0.6 & 120 & 0.2 & 9.9 \\
\hline Dynamic viscosity, $\mu(\mathrm{kg} / \mathrm{ms})$ & - & 0.001003 & - & - & - \\
\hline Latent heat, $H_{L}(\mathrm{~kJ} / \mathrm{kg})$ & - & - & - & 232 & 97 \\
\hline Solidus Temperature; $T_{s}\left({ }^{\circ} \mathrm{C}\right)$ & - & - & - & 16 & 16 \\
\hline Liquidus Temperature; $T_{1}\left({ }^{\circ} \mathrm{C}\right)$ & - & - & - & 19 & 19 \\
\hline
\end{tabular}

For the foam conductivity an experimental value was used, which was determined using a segment cut from the actual aluminium foam structure. The contribution of the PCM $(\lambda=0.2 \mathrm{~W} / \mathrm{m} / \mathrm{K})$ to the conductivity can be neglected as the expected contribution of the PCM-volume is with $<0.2 \mathrm{~W} / \mathrm{m} / \mathrm{K}$ within the experimental accuracy range of the conductivity measurement of the foam.

The transient simulation was performed by using ANSYS (Fluent) 19.1, to run a three-dimensional model. Due to the thermal and geometric symmetry along the cylinder axis, the computational domain was only $\frac{1}{4}$ part. The HTF modulation is based on the Navier-Stokes system of equations, which defines the conservation of mass, momentum and energy. As for the PCM/foam-composite the effect of natural convection was neglected; only the energy equation needs to be solved. Neglecting the convection is in accordance with the results of Sundarram et al. and Tian et al. who found no resp. very small convection effects due to the high viscosity of paraffin-based PCM and their low coefficient of expansion $[13,16]$. In the case of the presented experiments the viscosity is even higher because of the added thickener agent. The solidification of the PCM/foam-composite is modelled by using the enthalpy-porosity method according to [20]. Solidification of the PCM/foam-composite takes place from $19{ }^{\circ} \mathrm{C}$ to $16^{\circ} \mathrm{C}$, where the melt interface is not tracked explicitly, but a liquid-solid mushy zone is modelled as a pseudo porous zone. In this zone porosity decreases from 1 to 0 during solidification and the calculation refers to the lever rule. Due to the Reynolds number, it can be concluded that the experiments were performed between laminar and turbulent regime of the HTF. In the present 
work a low-Reynolds number version of the $\mathrm{K}-\varepsilon$ two-equation turbulence model was used, as it is known to give accurate results for the flow and heat transfer in the transitional regime [21,22]. The HTF temperature at the inlet was set to be consistent with the experimental data.

Initially, a temperature of $28{ }^{\circ} \mathrm{C}$ was set to the whole system as basic condition; the simulation was restricted to the discharging cycle.

The numerical model takes use of the following assumptions:

- the thermophysical properties of PCM/foam composite, HTF, and pipe material are constant,

- viscous heating and volume expansion are ignored,

- natural convection is neglected and

- the outer tube wall was considered thermally isolated.

The coupling between pressure and velocity is done by SIMPLE algorithm and PRESTO is adopted for pressure interpolation. The convective terms were discretised by using second order upwind interpolation scheme and for the energy equation the QUICK scheme was applied. The residual convergence criterions were set $10^{-7}$ for the energy equations and $10^{-6}$ for continuity and momentum equations. A convergence analysis of the numerical calculation was performed with 614,400, 777,600, and 1,586,400 elements and time steps of $0.2,1$ and $5 \mathrm{~s}$ with regard to the temperature at the outlet. The meshing grid of 777,600 elements and the time steps of 1 s were chosen as a compromise between accuracy and computational time.

\section{Results}

The results of the pressure loss measurements of the two storages are shown in Figure 6 . For the $26 \mathrm{p}$ storage at a $1 \mathrm{~L} / \mathrm{min}$ flow the loss is approximately $20 \mathrm{mbar}$, at $1.7 \mathrm{~L} / \mathrm{min} 200 \mathrm{mbar}$. The pressure loss for the 4 p storage is much smaller. e.g., to keep the loss at 20 mbar one can apply a volume flow of $2 \mathrm{~L} / \mathrm{min}$.

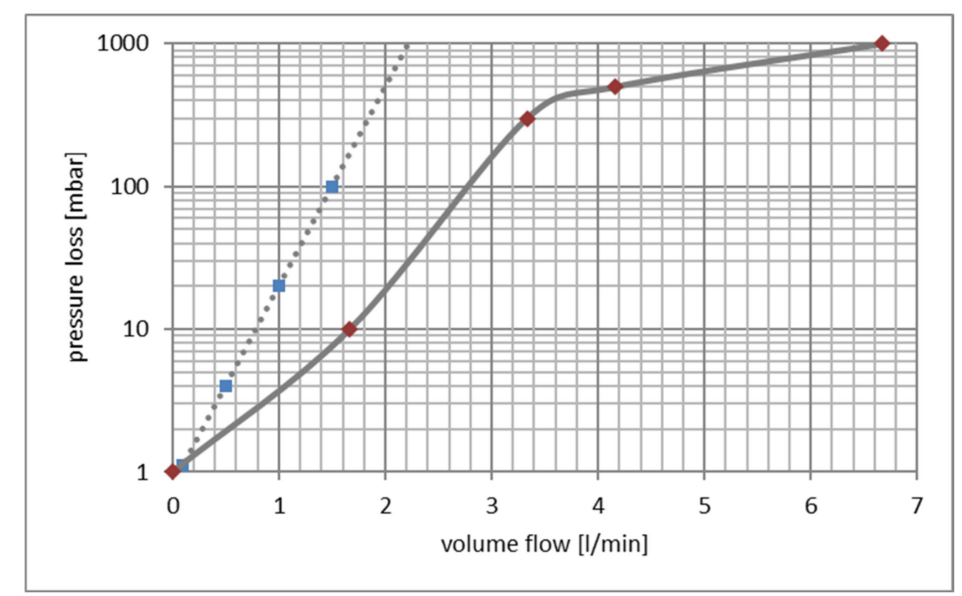

Figure 6. Pressure loss versus flow rate, dotted line: $26 p$, solid line: $4 p$.

As the thermostat used has only a small pumping capacity the maximum flow rate for the $26 \mathrm{p}$ storage was about $1.1 \mathrm{~L} / \mathrm{min}$. Therefore, in the subsequent power evolution measurements the water volume flow was varied only for the 4 p-system $(1.95 \mathrm{~L} / \mathrm{min}, 1.64 \mathrm{~L} / \mathrm{min}$, and $1.16 \mathrm{~L} / \mathrm{min})$, whereas for the $26 \mathrm{p}$-system the fluid flow was restricted to $1 \mathrm{~L} / \mathrm{min}$.

The results of the temperature measurements during the charging of the 26p and 4p systems are shown in Figure 7, results of the discharging experiment are shown in Figure 8. As could be expected, the temperature difference between inlet and outlet decreases with time and also with higher flow velocity as the retention time of the fluid in the storage system is smaller. The increase of the heat transfer coefficient between the water and the inner tube wall due to the increased flow velocity seems not to be high enough to balance the effect of the reduced retention time. The largest temperature 
differences between inlet and outlet are found for the 26p-system. This, again, can be attributed to the longer retention time of the fluid in the systems tubes in comparison to the $4 \mathrm{p}$-storage $(410 \mathrm{~cm}$ tube length vs. $240 \mathrm{~cm}$ ). In none of the $20 \mathrm{~K}$-experiments can a breaking point at $18{ }^{\circ} \mathrm{C}$ be seen in the course of the outlet temperature-time curve. Weak inflection points can be observed, e.g., at approximately $100 \mathrm{~s}$ and $600 \mathrm{~s}$ in the discharging outlet temperature curve of system $4 \mathrm{p}$ with $1.6 \mathrm{~L} / \mathrm{min}$ flow velocity (indicating that heat release of the PCM begins resp. ends at those times), see Figure 8. In comparison, the $4 \mathrm{~K}$-experiments show-after the initial period with changing inlet temperatures-almost constant outlet temperatures over the whole discharging and charging cycle.

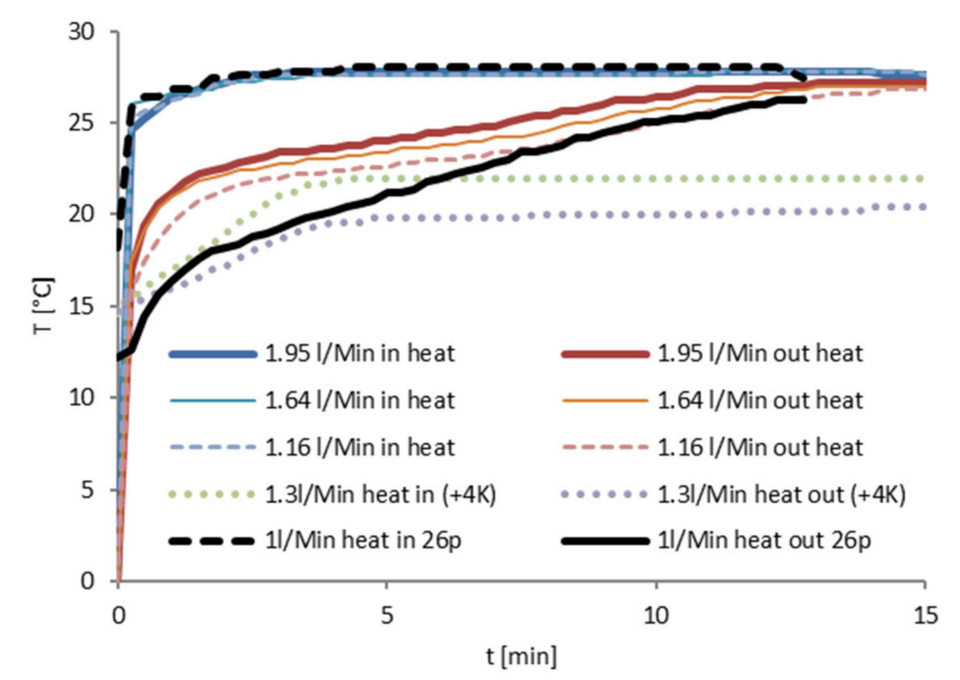

Figure 7. Temperature development during the charging of the storage, in: Water temperature before the storage, out: Water temperature after the storage.

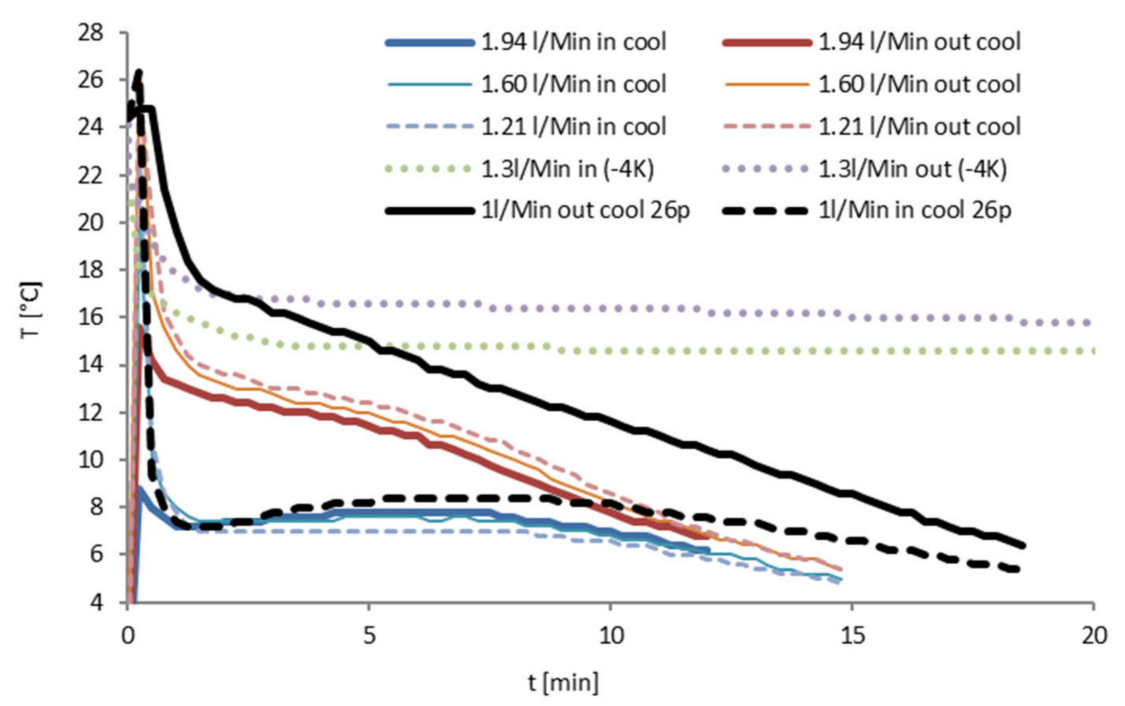

Figure 8. Temperature development during the discharging of the storage, in: Water temperature before the storage, out: Water temperature after the storage.

The resulting power input during charging and discharging of the systems are shown in Figures 9 and 10 . As can be seen there, the $26 \mathrm{p}$ system as well as the $4 \mathrm{p}$ system satisfy the benchmark of a power output respectively input of around $500 \mathrm{~W}$ for a period of $5 \mathrm{~min}$. The $26 \mathrm{p}$ system has initially the highest transfer power and lies generally somewhat above the measured power levels of the $4 p$ system. The latter can be attributed to the approximate $15 \%$ higher overall energy capacity of the $26 \mathrm{p}-$ in comparison to the $4 \mathrm{p}$-system. In the $4 \mathrm{p}$-system, the smallest volume flow of $1.16 \mathrm{~L} / \mathrm{min}$ leads to the lowest power input resp. output. Increasing the volume flow to about $1.64 \mathrm{~L} / \mathrm{min}$ increases the initial 
power but a further rate increase does not increase the power anymore. The $4 \mathrm{~K}$-experiments show a relatively constant transfer power concurring with the almost constant temperature differences shown in Figures 7 and 8.

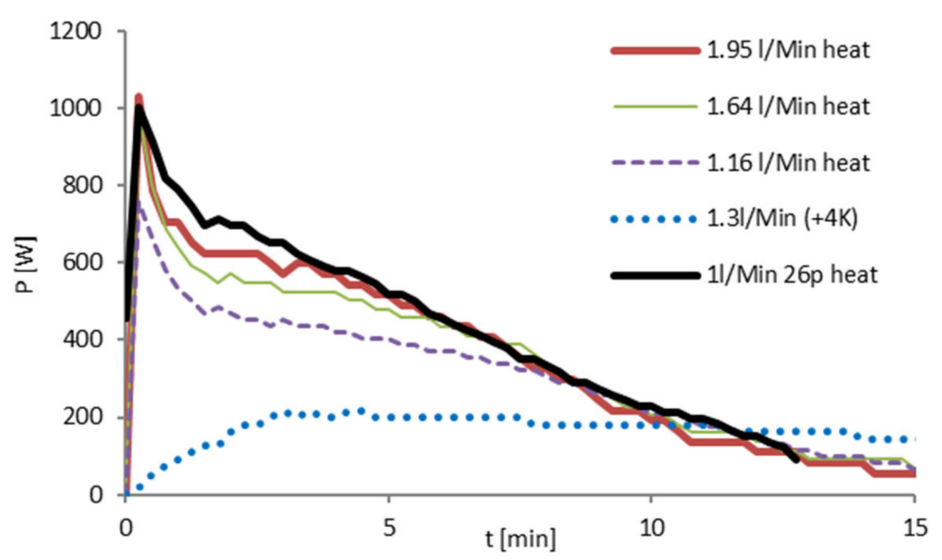

Figure 9. Power input into the storage during the charging.

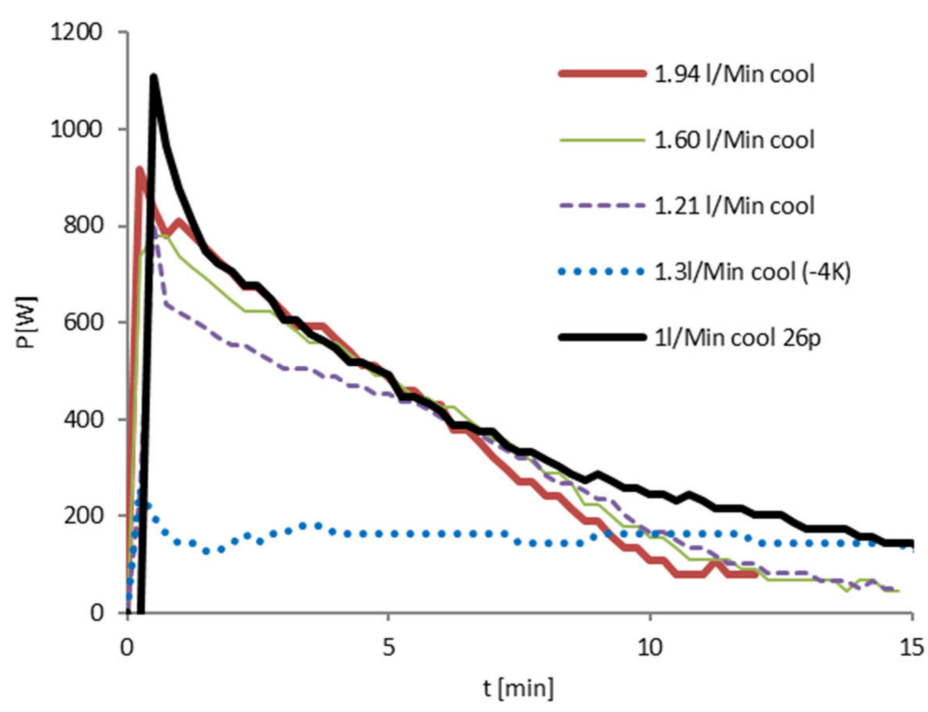

Figure 10. Power output from the storage during the discharging.

Stored and released heat quantities during the charging and discharging cycles are depicted in Figures 11 and 12, for a better comparison of the systems the transferred heat quantities are related to respective overall energy capacities. $1.95 \mathrm{~L} / \mathrm{min}$ and $1.64 \mathrm{~L} / \mathrm{min}$ curves of the $4 p$-system are on top of the various curves, i.e., the charging and discharging of the 4 -system is the fastest under those conditions. The curves of all $20 \mathrm{~K}$-experiments converge to an energy level of approximately $80 \%$. 


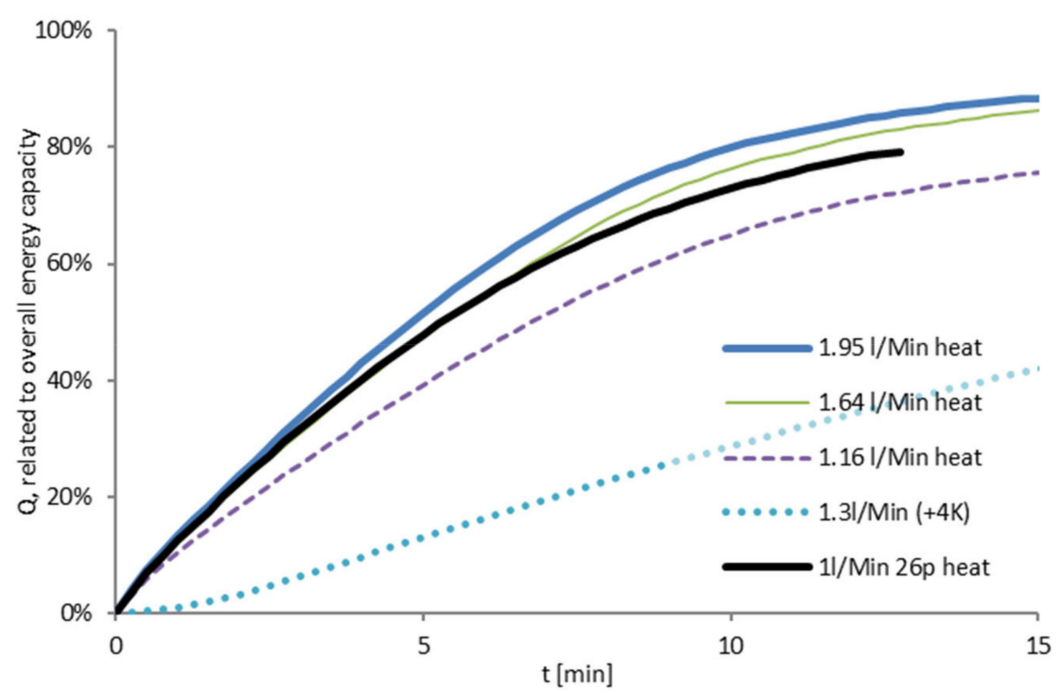

Figure 11. Stored heat quantity during the charging (in \% of overall energy capacity of the systems).

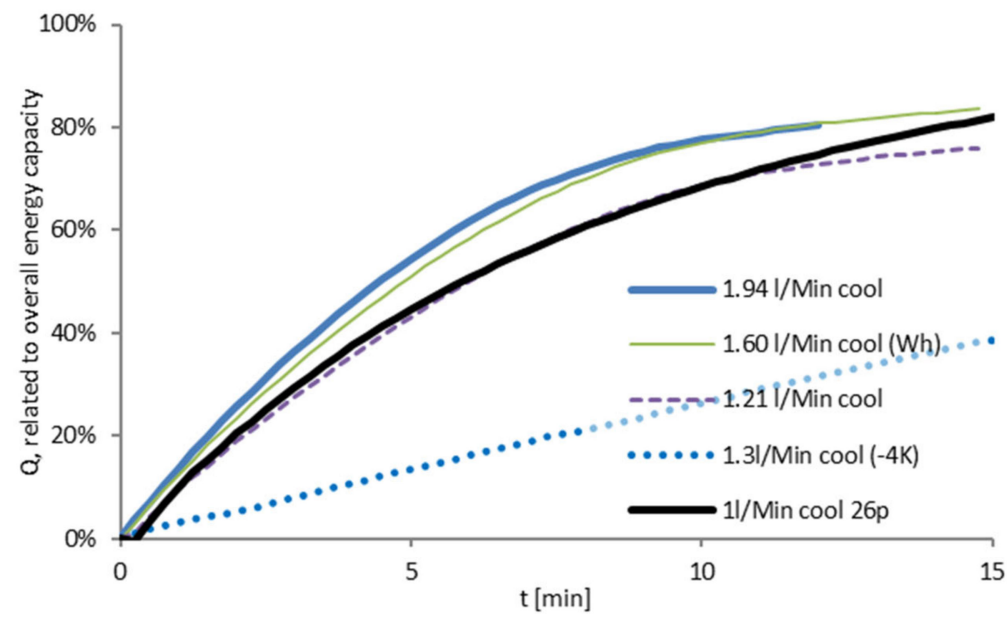

Figure 12. Released heat quantity during the discharging (in \% of overall energy capacity of the systems).

The results of the simulation of the discharging of the 4 p-system with a flow velocity of $1.6 \mathrm{~L} / \mathrm{min}$ are shown in Figure 13. Agreement of both curves is quite good. It has to be emphasized that no parameter adaption was done for the simulation. The fact that the simulated outlet temperatures lie somewhat higher than the experimental values can be explained by the position of the thermocouple in the experiment (bonded to the surface of the tube). The simulated values refer directly to the mean water temperature at the outlet. The liquid fraction of the overall PCM/foam domain is additionally indicated. It can be seen that the release of thermal energy from the solidification process is initialised after $20 \mathrm{~s}$ and complete solidification is reached after $720 \mathrm{~s}$. This concurs with the qualitative estimation done in the discussion of Figure 8. 


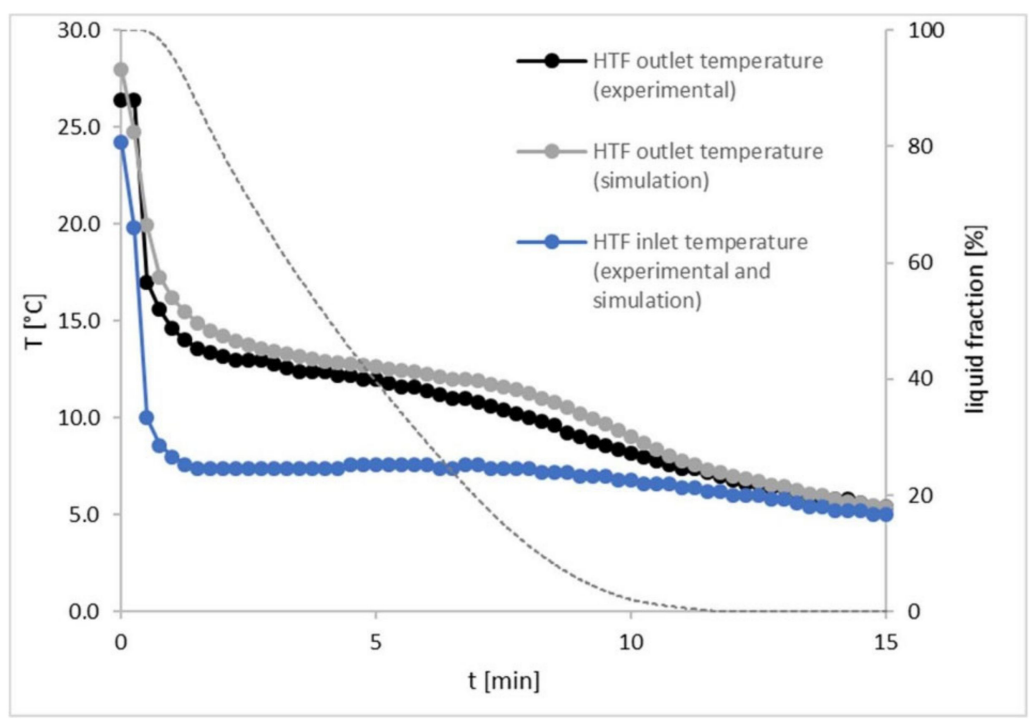

Figure 13. Comparison of the experimental and simulated outlet temperatures for the $4 \mathrm{p}$-system, flow velocity $1.6 \mathrm{~L} / \mathrm{min}$.

To set the liquid fraction in relation to the temperature distribution Figure 14 visualizes the cross section at the pipe length of $z=1.2 \mathrm{~m}$, which is the middle of the overall pipe length. On the left side the liquid fraction distribution shows that the center is liquid as it presents the fluid domain of the HTF. The subsequent solid domain represents the pipe. In the outer domain the PCM/Foam domain shows an gradient from solid to liquid with increasing distance from the pipe wall. This gradient is also visible in the temperature distribution at the right side of the drawing. The HTF reaches a temperature of approximately $9^{\circ} \mathrm{C}$ in the center, near the pipe wall a temperature of $13^{\circ} \mathrm{C}$ was determined. The region where the PCM/foam reaches a temperature of $16{ }^{\circ} \mathrm{C}$ concurs with the beginning of the semi-solid domain. The temperature difference between the interface to the pipe wall and the isolated outer surface of the cylinder is $5.2 \mathrm{~K}$, i.e., the mean temperature gradient in the PCM/foam domain is only $0.35 \mathrm{~K} / \mathrm{mm}$.
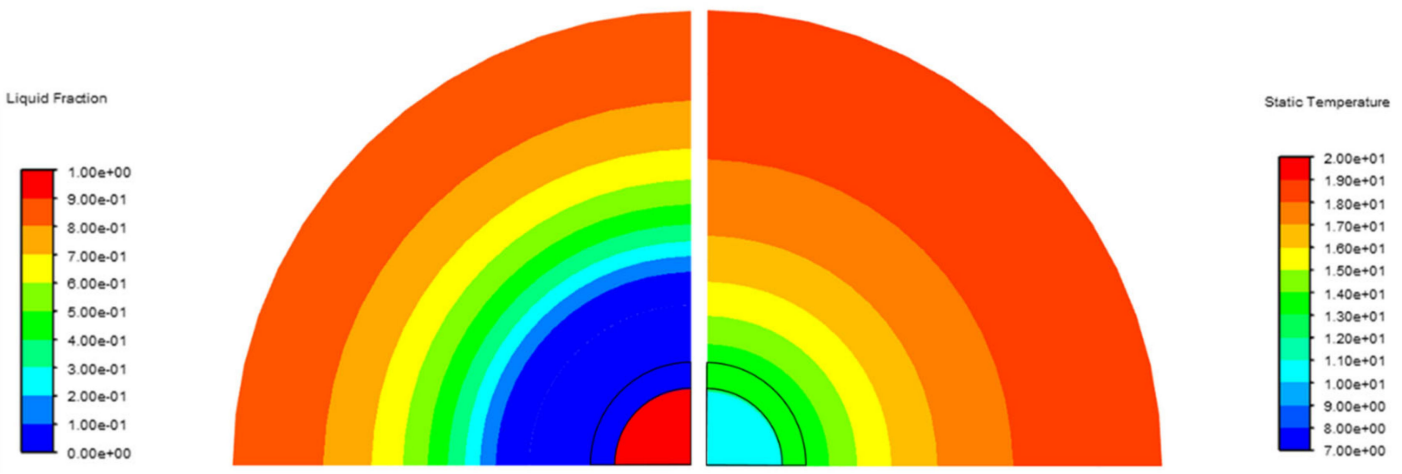

Figure 14. Comparison of the liquid fraction and temperature distribution at the cross-section of the modelled area at the middle of the pipe length of $z=1.2 \mathrm{~m}$ at $t=200 \mathrm{~s}$.

\section{Discussion}

For the chosen inner tube diameter of $6 \mathrm{~mm}$ and flow velocities in the range of approximately 1-2 L/min Reynold numbers indicate a flow regime which is transient between laminar and turbulent. Because of the rather complicated piping in the limited installation space with lots of connectors and bendings (especially in the case of the 26p-system) the flow is expected to be even more turbulent than specified by the Reynold number. The more complicated piping and the longer overall tube length explain simply the higher flow resistance of the 26p-demonstrator in comparison to the $4 \mathrm{p}$-system. 
Comparing the charging and discharging process it is evident that the storage reacts almost identically in both directions with the same $\Delta \mathrm{T}$ applied to the coolant. This is often not the case for PCM storages as the heat transfer mechanisms in the solid (only heat conduction) and liquid (conduction plus convection) PCM differ. This result corroborates that in the current setup with thickened PCM convection is impeded resp. does not contribute significantly to the overall thermal transport. As already mentioned, the specific production process for the aluminium foam leads to a very special structure (see Figure 15) which differs significantly from e.g., replicated strut-like metal foams [4]. In the present case, the foam resembles a bulk of almost spherical cells with connecting windows of limited size between neighbouring cells. This structure offers higher resistance to the formation of large-sized convection currents.

One consideration was that the volume decrease of the PCM during solidification would lead to the formation of internal pores and cracks in the PCM and the interface of PCM and aluminium foam-resulting in a worsened heat transfer between PCM and aluminium and thereby to a reduced power input during charging in comparison to the power output during discharging. However, the results of the tests give no indication of a significant influence of such effects.

The $4 p$ and the $26 p$ storage system exhibit slightly different maximum storage capacities. Still, a qualitative evaluation is possible. Comparing the temperatures at the storage exit in Figures 6 and 7 it is observed that the retention period of the coolant in the storage is insufficient to increase the coolant temperature to a value close to the melting/solidification point for the $4 \mathrm{p}$ storage. The latter is only the case for the smaller temperature difference applied $( \pm 4 \mathrm{~K})$ which is accompanied by lower power levels. For the $26 \mathrm{p}$ storage the outlet temperature is much closer to the melting/solidification point. For clarity this behaviour is also shown again in Figure 16 where the stored energy is related to the output temperatures for the heating resp. cooling process. In an ideal storage with no heat transfer limitation a clear holding point would be obser at $18^{\circ} \mathrm{C}$. Any deviation from an $18^{\circ} \mathrm{C}$ holding point shows the influence of the actual heat transfer taking place. If a small temperature difference $( \pm 4 \mathrm{~K})$ is applied, less heat needs to be transferred than for the larger temperature difference $( \pm 10 \mathrm{~K})$. Thus, the $\pm 4 \mathrm{~K}$ lines are closer to the $18^{\circ} \mathrm{C}$ than the $\pm 10 \mathrm{~K}$ lines for the $4 \mathrm{p}$ storage.

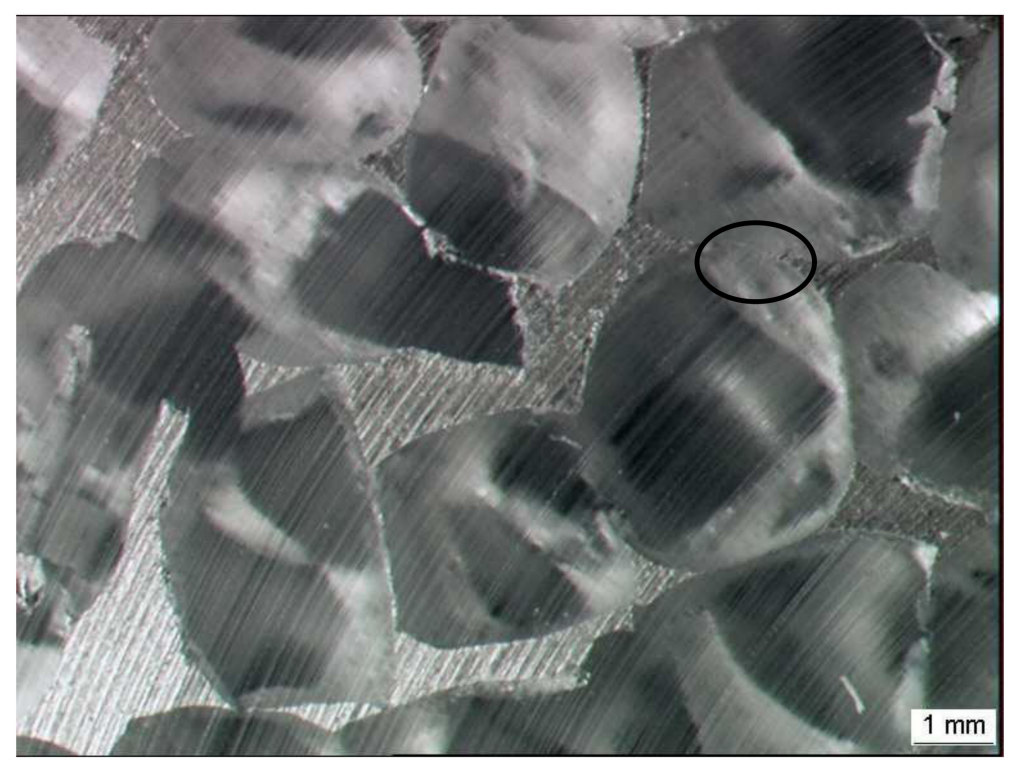

Figure 15. Cross-section of typical pore structure of aluminium foams used in the tests (for better visibility the picture was taken before removing the polymer placeholder, it is still in the structure). Connection window example marked with black circle. 


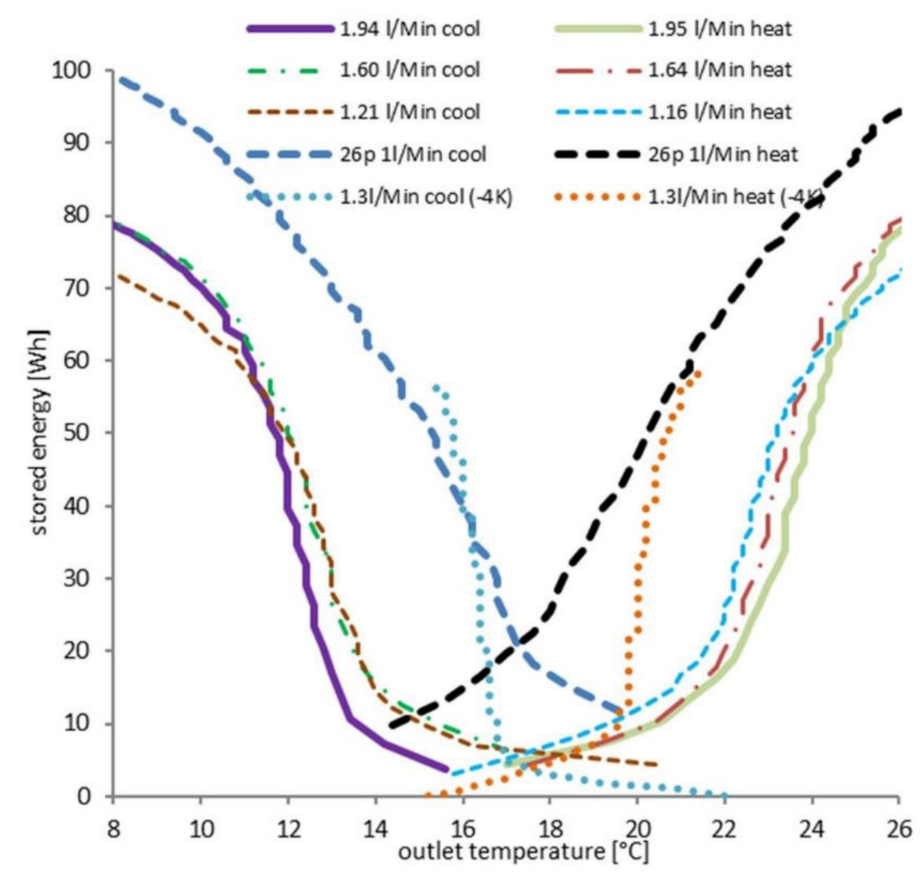

Figure 16. Delivered Heat Quantity depending on the temperature.

On the other hand, the $\mathrm{T}(\mathrm{t})$-curves of the $4 \mathrm{p}$-system show more clearly developed inflection points (see e.g., Figure 8 ) and are closer to the expected curve progression for systems with latent heat. Considering both effects-closeness to the melting temperature in one case and a more pronounced breaking point in the other-a qualitative conclusion can be that in the $26 \mathrm{p}$-system overall heat transfer is limited by the transport through the PCM-foam to the tube and that in the case of the 4p-system the limitation is the heat transfer to the water. Momentarily, this conclusion must, however, be a qualitative one as the system behaviour and, therefore, the difference between the $4 p$ and $26 p$ storages is influenced by more than one factor. e.g., the two porosities ( $75 \%$ in case of the $4 \mathrm{p}$ storage, $65 \%$ in the $26 \mathrm{p}$ storage) relate to different heat conductivities in the foam. In Figure 17 foams made from the alloy AlSi9Cu 3 are shown and their heat conductivity decreases from about $19 \mathrm{~W} / \mathrm{m}^{*} \mathrm{~K}$ to $11.5 \mathrm{~W} / \mathrm{m}^{*} \mathrm{~K}$ going from $65 \%$ to $75 \%$ porosity. Changing the porosity will, however, also change the volume fraction of PCM and of latent heat to be transferred. Changing the tube length in a system will not only change the retention time of the fluid in the tubes but also the mean distance of the foam with PCM to the tube.

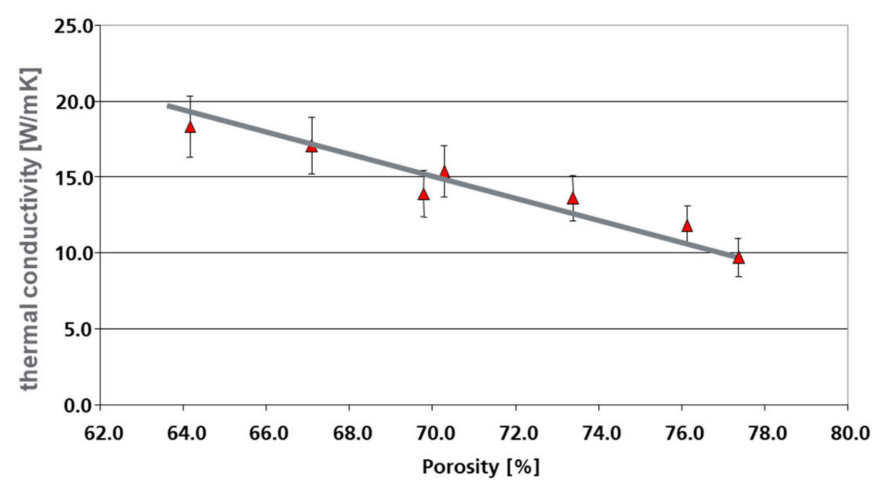

Figure 17. Dependence of thermal conductivity on Al foam porosity for the alloy AlSi9Cu3.

A later aspect might be the most important factor why the 4p-system has a better power out- resp. input, as shown in Figures 11 and 12. Referring to Figures 2 and 3 and to Table 1 one can see that the foam blocks of the $4 p$ and the $26 p$ system have very different aspect ratios (geometries of the foam blocks were predetermined by the systems installation space and the high pressure casting mould 
available for the project). The foams for the $26 \mathrm{p}$-system have a very high ratio of length and thickness. This leads to more disadvantageous thermal transport lengths to the integrated tubes. In comparison, the dimensions of the $4 \mathrm{p}$-foams allowed a more optimal design of the tube positions.

Keeping the aim of $500 \mathrm{~W}$ for $5 \mathrm{~min}$ in mind, the measurements of both storages (4p and 26p) are very promising for reaching this goal. The power outputs for different flow rates and both designs are above the threshold as long as the temperature difference during charging/discharging is sufficiently high. For smaller temperature differences, e.g., $\pm 4 \mathrm{~K}$ as shown, the charging/discharging process takes about $15 \mathrm{~min}$ for the same storage quantity. The power output varies strongly with the $\Delta \mathrm{T}$ between PCM storage and coolant whose temperature is determined by the available sources and sinks in the vehicle.

The simulation results, using a model with strongly simplified geometries for the 4p-PCM storage, showed - without parameter adaption - a good agreement with experimental results. It is concluded that such a model can be used for the further optimisation of the storage system, especially the adaption of foam porosity and of tube length in the storage.

One reason for the good agreement of experiment and simulation can be due to the in-situ integration of the HTF-system into the foam structure. The specific production method simplifies the bonding of tube and foam and improves significantly the heat transfer between both. Atal et al. indicate the importance of this aspect [8]. Nevertheless, in many investigations bonding of foam and HTF has not been carried out, e.g., [6-8]. However, in the case of non-bonding of foam and tube it can be expected that at the tube-foam-interface a layer forms with a thickness of few tenths of $\mathrm{mm}$, which consists almost exclusively of PCM and exhibits the low thermal conductivity of the PCM. In the case of a well-conducting foam as in the presented experiments the resistance of such layer may contribute significantly to the overall thermal resistance and can not be neglected.

Because the experiments were carried out on demonstrator level with relatively complicated HTF-piping design in the foam a detailed comparison to the work of other groups is difficult. However, the main results of our work blend well into the results of the literature, especially the significant reduction of loading and unloading times of the storage systems by the introduction of foam and the low significance of convection in the overall thermal transport. The large reduction of thermal gradients in the foam-PCM area and the increased importance of the heat transfer into the HTF in comparison to conventional PCM systems agree well with the results of e.g., Chen et al. and Esapour et al. [9,15]. Esapour's results indicated, followingly, a relative robustness of the system behaviour against variations of the position of HTF-tubes. This effect might be considered also for the systems investigated in our work and leaves opportunities for future simplifications of the design and production of the in-situ integrated HTF-pipe installation.

\section{Conclusions}

The integration of aluminium foams into PCM storage systems allows complying with the HVAC system requirements of an electric vehicle regarding power, capacity and temperature range. Two different store systems, consisting of 26 foam and of 4 foam pieces were produced and submitted to lab performance tests, because the lower block number installation of the 4-piece system is easier and pressure loss in the fluid system is lower. The measured temperature-time curves indicate that the main limitations for the thermal transport are the thermal diffusion from the PCM to the tube in the case of the 26p-system and the heat transfer from the inner tube wall to the liquid in the case of the simpler 4p-system.

Author Contributions: Conceptualization: E.K., J.B.; Investigation: E.K., G.L., J.B., J.W.; Simulation: J.W., S.M.; Writing: all; All authors have read and agreed to the published version of the manuscript.

Funding: The QUIET project has received funding from the European Union's Horizon 2020 research and innovation programme under grant agreement No. 769826. The content of this publication is the sole responsibility of the QUIET consortium partners and does not necessarily represent the view of the European Commission or its services. 
Conflicts of Interest: The authors declare no conflict of interest.

\section{References}

1. Osterman, E.; Tyagi, V.V.; Butala, V.; Rahim, N.A.; Stritih, U. Review of PCM based cooling technologies for buildings. Energy Build. 2012, 49, 37-49. [CrossRef]

2. Souayfane, F.; Fardoun, F.; Biwole, P. Phase change materials (PCM) for cooling applications in buildings: A review. Energy Build. 2016, 129, 396-431. [CrossRef]

3. Laguerre, O.; Ben Aissa, M.F.; Flick, D. Methodology of temperature prediction in an insulated container equipped with PCM. Int. J. Refrig. 2008, 31, 1063-1072. [CrossRef]

4. Wang, W.; Yang, X.; Fang, Y.; Ding, J.; An, J. Enhanced thermal conductivity and thermal performance of form-stable composite phase change materials by using b-aluminum nitride. Appl. Energy 2008, 86, 1196-1200. [CrossRef]

5. Munoz-Sanchez, B.; Iparraguirre-Torres, I.; Madina-Arrese, V.; Izagirre-Etxeberria, U.; Unzurrunzaga-Iturbe, A.; Garcia-Romero, A. Encapsulated high temperature PCM as active filler material in a thermocline-based thermal storage system. Energy Procedia 2015, 69, 937-946. [CrossRef]

6. Cui, H.T. Experimental investigation on the heat charging process by paraffin filled with, high porosity copper foam. Appl. Therm. Eng. 2012, 39, 26-28. [CrossRef]

7. Dukhan, N.; Bodke, S. An improved PCM heat storage technology utilizing metal foam. In Proceedings of the 12th IEEE Intersociety Conference on the Thermal and Thermomechanical Phenomena in Electronic Systems (ITHERM), Las Vegas, NV, USA, 2-5 June 2010.

8. Atal, A.; Wang, Y.; Harsha, M.; Sengupta, S. Effect of porosity of conducting matrix on a phase change energy storage device. Int. J. Heat Mass Transf. 2016, 93, 9-16. [CrossRef]

9. Chen, X.; Li, X.; Xia, X.; Sun, C.; Liu, R. Thermal Performance of a PCM-Based Thermal Energy Storage with Metal Foam Enhancement. Energies 2019, 12, 3275. [CrossRef]

10. Klemm, T.; Hassabou, A.; Abdallah, A.; Andersen, O. Thermal energy storage with phase change materials to increase the efficiency of solar photovoltaic modules. Energy Procedia 2017, 135, 193-202. [CrossRef]

11. Dmitruk, A.; Naplocha, K.; Grzęda, J.; Kaczmar, J.W. Aluminum Inserts for Enhancing Heat Transfer in PCM Accumulator. Materials 2020, 13, 415. [CrossRef] [PubMed]

12. Mehling, H.; Hiebler, S.; Ziegler, F. Latent heat storage using a PCM-graphite composite material. In Proceedings of the TERRASTOCK 2000, Stuttgart, Germany, 28 August-1 September 2000.

13. Sundarram, S.S.; Li, W. The effect of pore size and porosity on thermal management performance of phase change material infiltrated microcellular metal foams. Appl. Thermal Eng. 2014, 64, 147-154. [CrossRef]

14. Baumeister, J.; Weise, J. Thermal management solutions using open porous metal structures, QUIET Workshop-Efficient and user-friendly designed electric vehicles "How breakthrough HVAC and other technologies enable enhanced thermal comfort solutions while increasing the driving range". In Proceedings of the 14th SDEWES Conference, Dubrovnik, Croatia, 1 October 2019.

15. Esapour, M.; Hamzehnezhad, A.; AliRabienataj Darzi, A.; Jourabian, M. Melting and solidification of PCM embedded in porous metal foam in horizontal multi-tube heat storage system. Energy Convers. Manag. 2018, 171, 398-410. [CrossRef]

16. Tian, Y.; Zhao, C.Y. A numerical investigation of heat transfer in phase change materials (PCMs) embedded in porous metals. Energy 2011, 36, 5539-5546. [CrossRef]

17. Körner, C.; Schwankl, M.; Himmler, D. Aluminum-aluminum compound castings by electroless deposited zinc layers. J. Mater. Process. Technol. 2014, 214, 1094-1101. [CrossRef]

18. Rübner, M.; Günzl, M.; Körner, C.; Singer, R.F. Aluminium-aluminium compound fabrication by high pressure die casting. Mater. Sci. Eng. A 2011, 528, 7024-7029. [CrossRef]

19. Berg, A.; Baumeister, J.; Rausch, G.; Busse, M.; Schnabel, L.; Bauer, J. Application of Aluminium Sponges in the Adsorption Refrigeration Engineering. Porous metals and metallic foams. In MetFoam 2007, Proceedings of the Conference on Porous Metals and Metallic Foams, Montreal, QC, Canada, 5-7 September 2007; Lefebvre, L.P., Banhart, J., Dunand, D.C., Eds.; DESTech Publication: Lancaster, PA, USA, 2008; pp. 493-496.

20. Voller, V.R.; Prakash, C. A fixed grid numerical modelling methodology for convection-diffusion mushy region phase-change problems. Int. J. Heat Mass Transf. 1987, 30, 1709-1719. [CrossRef] 
21. Huiren, Z.; Songling, L. Numerical simulation of transitional flow and heat transfer in a smooth pipe. Int. J. Heat Mass Transf. 1991, 34, 2475-2482.

22. Gorji, S.; Seddighi, M.; Ariyaratne, C.; Vardy, A.E.; O’Donoghue, T.; Pokrajac, D.; He, S. A comparative study of turbulence models in a transient channel flow. Comput. Fluids 2014, 89, 111-123. [CrossRef]

Publisher's Note: MDPI stays neutral with regard to jurisdictional claims in published maps and institutional affiliations.

(C) 2020 by the authors. Licensee MDPI, Basel, Switzerland. This article is an open access article distributed under the terms and conditions of the Creative Commons Attribution (CC BY) license (http://creativecommons.org/licenses/by/4.0/). 